\title{
Sensitivity to environmental irritants and quality of life in COPD
}

This article was published in the following Dove Press journal:

International Journal of COPD

8 December 201 I

Number of times this article has been viewed

\section{Ewa Ternesten-Hasséus \\ Sven Larsson \\ Eva Millqvist}

Department of Internal Medicine/ Respiratory Medicine and Allergology, Sahlgrenska Academy, University of Gothenburg, Gothenburg, Sweden
Correspondence: Eva Millqvist Department of Internal Medicine/ Respiratory Medicine and Allergology, University of Gothenburg, Sahlgrenska University Hospital, Bruna Stråket

II B, SE 41345 Gothenburg, Sweden

Tel +46708433819

Fax +46 3I 824904

Email eva.millqvist@medfak.gu.se
Abstract: It is a common clinical experience that patients with chronic obstructive pulmonary disease (COPD) complain of airway symptoms provoked by environmental irritants like chemicals and scents, although few studies can confirm such connections. The aim was to study the prevalence of airway symptoms induced by chemicals and scents in a group of patients with newly diagnosed CPOD and to analyze any relation to illness severity and quality of life. Eighty-one patients with COPD were recruited to the study. By mail they were asked to answer three questionnaires regarding symptoms, quality of life, and social and emotional influence of airway symptoms induced by environmental irritants. A majority (62\%) of the COPD patients claimed to be hyperreactive to chemicals and scents. As a group they scored higher on a questionnaire measuring social and emotional influences of such environmental irritants compared to healthy control subjects. Further, high scores were more common among patients with a very severe form of COPD and among patients with regular use of $\beta_{2}$-stimulants. High scores were also associated with significantly more airway symptoms and, in some aspects, with impaired quality of life. In conclusion, the results of this study show that airway symptoms induced by environmental irritants are common in patients with COPD and that this increased airway sensitivity follows the impairment of lung capacity. The mechanisms behind this remain unclear.

Keywords: COPD, hyperresponsiveness, environmental irritants, sensory hyperreactivity, quality of life

\section{Introduction}

It is a common clinical experience that patients with chronic obstructive pulmonary disease (COPD) complain of airway symptoms provoked by environmental irritants like chemicals and scents, although few studies can confirm such connections. An indirect method to measure sensory nerve responsiveness to environmental irritants is to measure the cough outcome to inhaled capsaicin. ${ }^{1,2}$ Capsaicin (8-methyl- $N$-vanillyl6-nonenamide), the ingredient that produces the heat in hot chili, is a well-known cough-inducing agent when inhaled. ${ }^{2,3}$ Cough reflex sensitivity to capsaicin in patients with COPD has been recorded in only a few studies with small groups of patients, and was reported to be normal or increased..$^{4-6}$

Upper and lower airway symptoms induced by chemicals and scents is a frequent problem in society, and sometimes the experienced symptoms are excessive, leading individuals to seek health care. ${ }^{7,8}$ In a subgroup of patients without COPD, asthma, or allergy, such symptoms in combination with increased cough sensitivity to inhaled capsaicin, known to stimulate the airway sensory nerves, have been identified.9.10 
A suggested name for the condition is "sensory hyperreactivity (SHR)," and it affects more than $6 \%$ of the adult population in Sweden. ${ }^{11}$

The Chemical Sensitivity Scale for SHR (CSS-SHR) was developed in order to quantify self-reported affective reactions to and behavioral disruptions by odorous/pungent substances. ${ }^{12}$ The eleven items of the CSS-SHR were found to generate approximately normal distributions, have good test-retest reliability, good internal consistency and predictive and concurrent validity, and to be unidimensional. The metric properties were satisfying despite the few items. In a random general population of adults, the prevalence of such problems, defined as a CSS-SHR score $\geq 43$, was $19 \%$ with an increased risk for female gender (odds ratio $=2.3) .{ }^{13}$

There are a lot of studies on quality of life in COPD; the instruments to measure this could simply be divided into either generic or disease-specific health measures. ${ }^{14}$ The Nottingham Health Profile (NHP) is a well-known and well-tested generic measure instrument that has been used for a number of different conditions to measure the "impact on well-being" - how disease and symptoms affect the patient's health, well-being, and ability to function in daily life. ${ }^{15,16} \mathrm{NHP}$, which focuses on questions concerning patients suffering from different chronic illnesses, has been shown to have both high validity as well as reliability. ${ }^{17}$ In COPD, the NHP showed strong relation to clinical and physical parameters. ${ }^{18,19}$ Bilingual health care personnel have translated the NHP from English to Swedish, with the aim of expressing how patients experience the effects of illness, as stated in their own words.

The aim was to study the prevalence of airway symptoms induced by chemicals and scents in a group of patients with newly diagnosed CPOD and to analyze any relation to illness severity. Further, the aim was to measure the social and emotional influence of airway symptoms induced by environmental irritants in COPD and to study if any influence is related to quality of life.

\section{Methods}

\section{Participants}

From the Department of Respiratory Medicine and Allergy at the Sahlgrenska University Hospital in Gothenburg, Sweden, 124 consecutive patients between 40-75 years of age were invited by mail to take part in the study. A pilot group of 18 patients was recruited from August 1, 2005 to October 31, 2005 and the rest of the data were collected from June 1, 2006 to September 18, 2007. All patients had a new diagnosis of COPD and were originally referred to the clinic due to increasing respiratory symptoms. The patients fulfilled international criteria for $\mathrm{COPD}^{20}$ and had the diagnosis code for COPD set by a doctor specializing in pulmonary diseases. The patients were reminded once to complete the questionnaire, and in some cases, at patient request, new questionnaires were sent out or patients were phoned to complete answers. After this, 26 had not answered and 17 informed that they did not want to take part in the study, leaving 81 responders $(65 \%)$. All patients had smoked for more than 10 years and 17 were still smokers. Demographic data are given in Table 1.

\section{Questionnaires}

Three questionnaires were sent by mail to the patients with a covering letter, informed consent form, and a prepaid envelope. The patients were asked to answer the questions according to their actual current condition.

1. The participants were asked to evaluate symptoms on a scale of $0-3$ ( $0=$ no symptoms, $1=$ mild symptoms, $2=$ moderate symptoms, and $3=$ severe symptoms). Seven symptoms were analyzed: heavy breathing, difficulty to get air, cough, chest pressure, phlegm, hoarseness,

Table I Demographic data for $8 \mathrm{I}$ patients with chronic obstructive pulmonary disease; median values and ranges, within brackets, are given

\begin{tabular}{|c|c|c|c|c|c|c|c|c|}
\hline $\begin{array}{l}\text { Male/female } \\
\text { (\%) }\end{array}$ & $\begin{array}{l}\text { Age } \\
\text { (years) }\end{array}$ & Pack years & $\begin{array}{l}\text { FEV } \\
\text { (\% pred) }\end{array}$ & $\begin{array}{l}\text { FVC } \\
\text { (\% pred) }\end{array}$ & FEV $\%$ & $\begin{array}{l}* A C \\
(\%)\end{array}$ & $\begin{array}{l}\text { *ICS } \\
(\%)\end{array}$ & $\begin{array}{l}* \beta_{2} \text {-stim } \\
(\%)\end{array}$ \\
\hline \multirow[t]{5}{*}{$43 / 38$} & 66 & 38 & 48 & 84 & 46 & 77 & 73 & 65 \\
\hline & $(47-75)$ & $(6-90)$ & $(16-84)$ & $(36-122)$ & $(19-78)$ & & & \\
\hline & \multicolumn{8}{|c|}{ Severity of COPD } \\
\hline & \multirow{2}{*}{\multicolumn{2}{|c|}{$\begin{array}{l}\text { Mild } \\
\text { FEV }_{1} \geq 80 \% \text { pred }\end{array}$}} & \multirow{2}{*}{\multicolumn{2}{|c|}{$\begin{array}{l}\text { Moderate } \\
\text { FEV, } 50 \%-80 \% \text { pred }\end{array}$}} & \multirow{2}{*}{\multicolumn{2}{|c|}{$\begin{array}{l}\text { Severe } \\
\text { FEV, } 30 \%-50 \% \text { pred }\end{array}$}} & \multirow{2}{*}{\multicolumn{2}{|c|}{$\begin{array}{l}\text { Very severe } \\
\text { FEV }_{1}<30 \% \text { pred }\end{array}$}} \\
\hline & & & & & & & & \\
\hline Number & \multicolumn{2}{|l|}{2} & \multicolumn{2}{|l|}{33} & \multicolumn{2}{|l|}{35} & \multicolumn{2}{|l|}{11} \\
\hline
\end{tabular}

Note: *Receiving regular treatment with anticholinergics, inhaled corticosteroids, $\beta_{2}$-stimulants.

Abbreviations: AC, anticholinergics; $\beta_{2}$-stim, $\beta_{2}$-stimulants; $F E V_{1}$, forced expiratory volume in I second; FEV \%, ratio of forced expiratory volume in I second to forced vital capacity; FVC, forced vital capacity; ICS, inhaled corticosteroids; pred, predicted. 
and tiredness. They were further asked whether chemicals and scents induced airway symptoms (yes or no).

2. The CSS-SHR questionnaire was used to quantify affective and behavioral consequences of odor intolerance. ${ }^{12}$ Selected from among a larger number of items about odor intolerance, the CSS-SHR consisted of eleven statements/ questions (Table 2) that are particularly sensitive for discriminating SHR patients from controls. The unweighted sum of all eleven items makes up the individual's total CSS-SHR score (ranging from 1-55 points; a high score indicating severe odor intolerance and $\geq 43$ points is regarded as a cutoff value). A control group also answered the CSS-SHR questionnaire. It consisted of 29 subjectively healthy nonsmoking subjects ( 14 women and 16 men) aged between $48-76$ years with a median age of 62 years. Sex and age of the control subjects did not differ from the patients. Controls were screened using questions on airway symptoms and symptoms in response to chemicals and scents. None of the controls had a history of allergy or symptoms in response to chemicals, scents, cold air, allergy, asthma, or COPD. No further medical examination was performed.

3. The Nottingham Health Profile measures "the subjective impact of disease" and was developed at Nottingham University. ${ }^{16,21-23}$ It consists of two parts, with part I containing 38 statements categorized in six areas: physical mobility, pain, sleep disturbance, lack of energy, emotional reaction, and social isolation. The questions are

Table 2 Items on the Chemical Sensitivity Scale for Sensory Hyperreactivity (CSS-SHR)

A. I would not mind living on a street with odorous/pungent car exhausts if the apartment I had was nice. ${ }^{\text {a }}$

B. I am more aware of odorous/pungent substances than I used to be.,

C. At movies, other persons' perfume and aftershave disturb me., ${ }^{a, b}$

D. I am easily alerted by odorous/pungent substances. ${ }^{\mathrm{a}, \mathrm{b}}$

E. I get used to most odorous/pungent substances without much difficulty. ${ }^{a}$

F. How much would it matter to you if an apartment you were interested in renting was located close to a factory that emits odorous/pungent substances? ? $^{\mathrm{b}, \mathrm{c}}$

G. In public places, I do not mind some smell of cigarette smoke. ${ }^{a}$

$\mathrm{H}$. There are often times when I want a complete odor-free environment. ${ }^{\mathrm{a}, \mathrm{b}}$

I. I find it hard to relax in a place that evokes odor/pungent sensations. ${ }^{\mathrm{b}, \mathrm{d}}$

J. I would not mind living in an apartment that has a weak smell. ${ }^{a}$

K. I am sensitive to odorous/pungent substances. ${ }^{a, b}$

Notes: a Scale: agree strongly (0), agree (I), agree mildly (2), disagree mildly (3), disagree (4), disagree strongly (5). The numbers in parentheses refer to the score given for that response; bitem scored in opposite direction before responses are summed; 'scale: it would completely deter me (0), or it would be very important ( 1 ), important (2), slightly important (3), or not important at all (4); ${ }^{d}$ scale: always (0), very often (I), often (2), occasionally (3), seldom (4), never (5). answered with yes or no, depending on whether it fits the individual's current situation. Reference values for part I were developed by weighting each question, which means that positive responses to all questions within an area equals 100 , and negative responses to all questions equals zero. The weighting procedure is based on Thurstone's "paired comparison" method. ${ }^{24}$ For the total score on part I, or NHP total (the sum of questions 1-38 multiplied by their weights), the sum is divided by six to reach a value between zero and 100. NHP part II contains seven questions (yes or no) concerning the impact of health problems on the individual's social function with regard to: paid employment, housework, social life, family life, sex life, hobbies, and holidays. For part II, the proportion of positive responses for each of the seven questions was calculated separately and compared with the control group. Due to the age profile of the patients, the question regarding employment was excluded. The patients were encouraged to answer the questions based on how they felt during the last week. One basic rule for the NHP is that it must be self-administered. ${ }^{17}$

\section{Statistical methods}

Median values and ranges were analyzed. Comparisons between patients and controls regarding the CSS-SHR questionnaire and within the COPD-group were performed with the Mann-Whitney $U$-test. For NHP part I, the MannWhitney $U$-test was used for comparison of two independent groups, and for part II, Pearson's chi-square test.

The work described in this article was carried out in accordance with World Medical Association's Declaration of Helsinki: Ethical Principles for Medical Research Involving Human Subjects. ${ }^{25}$ Informed consent was obtained from all patients at the start of the investigation, and the Regional Ethical Review Board of Gothenburg, Sweden approved the study.

\section{Results Symptoms}

Fifty patients (62\%) claimed, by a yes answer, to have airway symptoms induced by chemicals and scents.

The patients' symptom scores are described in Figure 1. The symptoms with the highest scores were heavy breathing, difficulty in getting air, and tiredness.

\section{NHP}

In part I, there was a significant deviation from the control group regarding energy, isolation, and mobility $(P<0.001)$ 


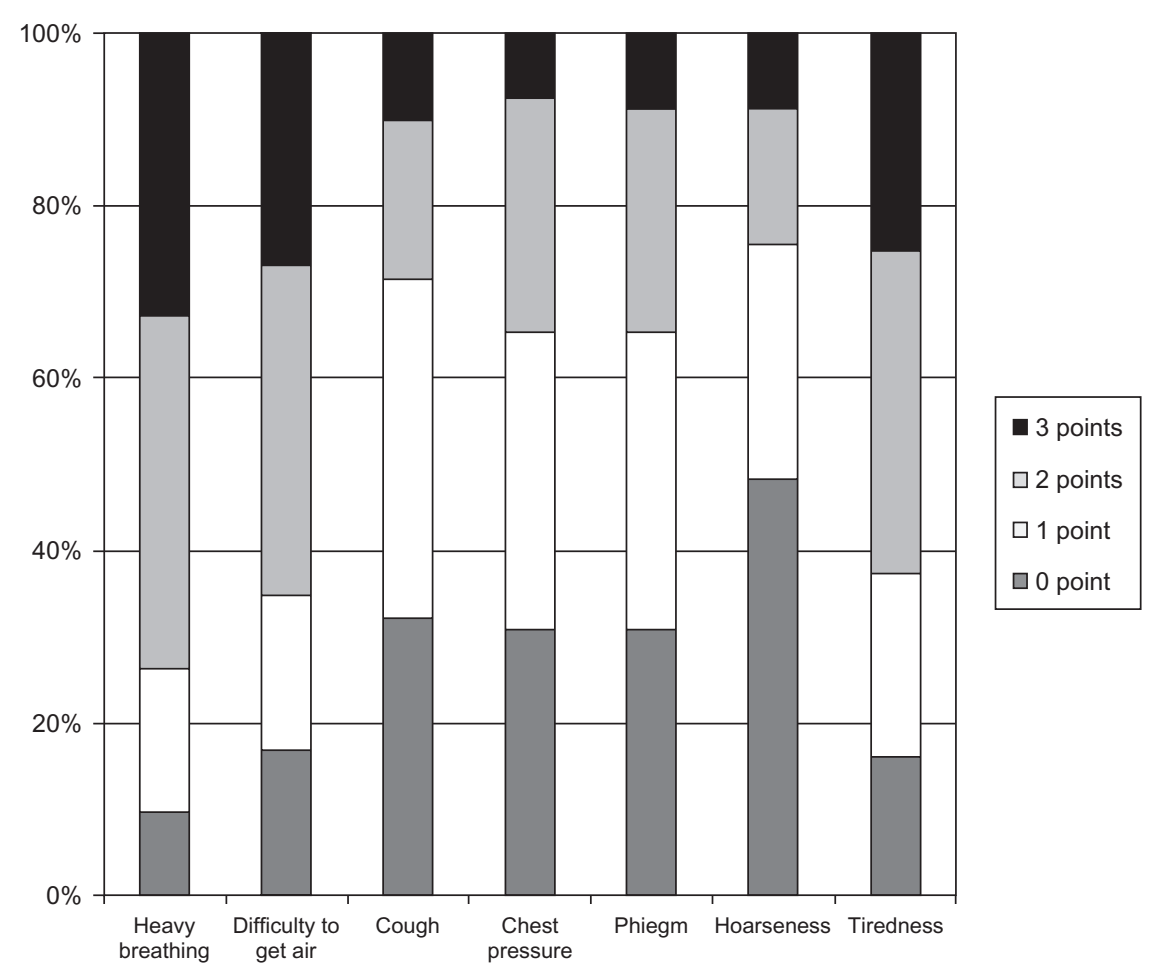

Figure I Evaluation of seven symptoms on a scale of $0-3(0=$ no symptoms, I = mild symptoms, $2=$ moderate symptoms, and $3=$ severe symptoms $)$ in $8 \mathrm{I}$ patients with chronic obstructive pulmonary disease.

and from the total score $(P<0.01)$. Part II demonstrated a significant difference between the patient group and the control group for the question regarding housework $(P<0.001)$. There was no deviation between the patient and control groups with regard to family life, hobbies, holidays, and sex life.

\section{CSS-SHR}

The patients' median CSS-SHR score was 34 (11-51). Male patients did not differ from females. Patients with very severe COPD had significantly higher scores than patients with moderate COPD $(P<0.05)$. Among the controls, the median CSS-SHR value was 27 (11-44); this differed significantly from the results of the patients $(P<0.005)$ (Figure 2).

\section{Differences between patients with high and low CSS-SHR score}

Twenty patients (25\%) (twelve men and eight women) had a score of $\geq 43$ points; thus exceeding the cutoff value for the score. ${ }^{12}$ The patients were divided into two groups according to the cutoff value: those who had a score of $\geq 43$ points and those with lower scores.

There were more patients with a score of $\geq 43$ points among patients with very severe COPD compared to those with moderate illness $(P<0.05)$ (Figure 3). High-scoring patients differed significantly from low-scoring participants regarding symptoms of heavy breathing $(P<0.01)$, difficulty getting air $(P<0.001)$, chest pressure $(P<0.05)$, and hoarseness $(P<0.01)$. Patients with high scores

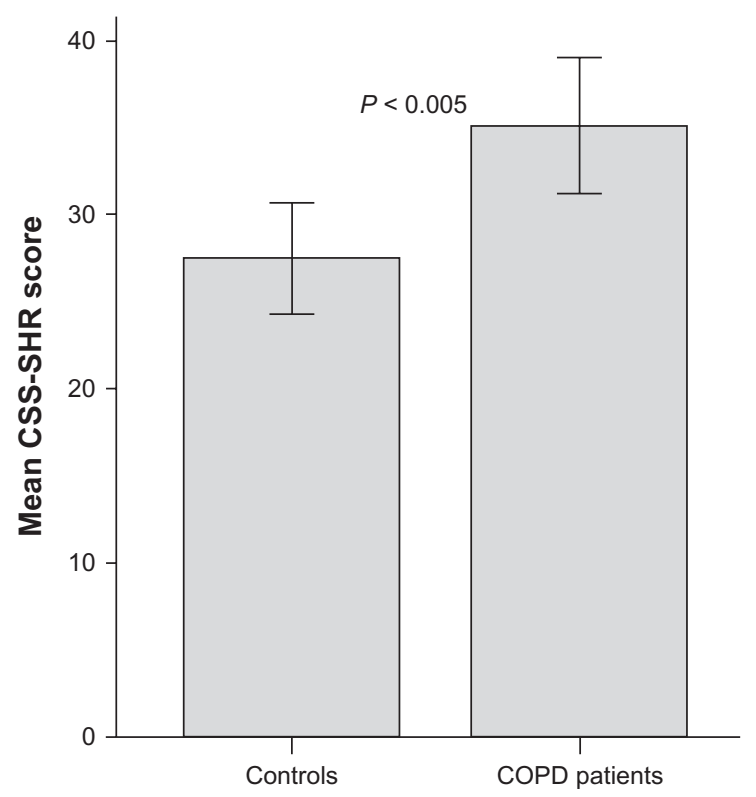

Figure 2 Mean Chemical Sensitivity Scale for Sensory Hyperreactivity (CSS-SHR) score ( \pm 2 standard errors of the mean) in $8 \mathrm{I}$ chronic obstructive pulmonary disease (COPD) patients and 30 control subjects. 


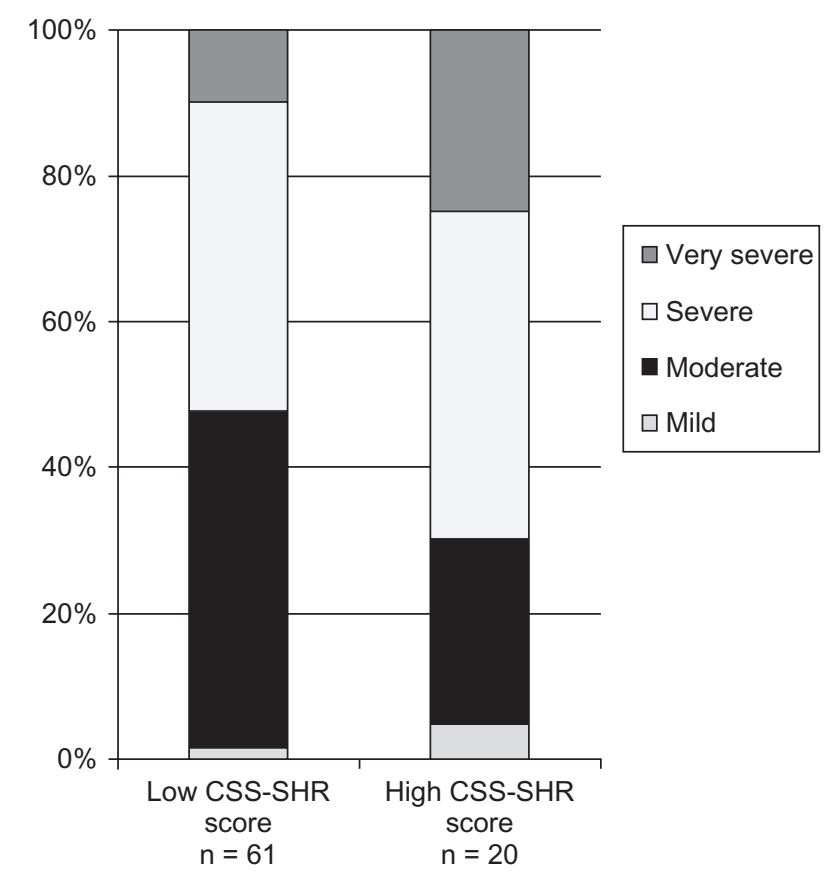

Figure 3 Comparison of the distribution of chronic obstructive pulmonary disease severity (mild, moderate, severe, very severe) in patients with low ( $<43$ points, $\mathrm{n}=6 \mathrm{I}$ ) or high Chemical Sensitivity Scale for Sensory Hyperreactivity (CSS-SHR) score $(n=20)$.

took $\beta_{2}$-stimulants regularly $(P<0.05)$ more often than those with low scores.

For NHP part I, patients with a high CSS-SHR score differed significantly from low-scoring participants in the domains of energy $(P<0.05)$, mobility $(P<0.01)$, and with pain $(P<0.05)$.

Regarding age, sex, pack years, and treatment with inhaled steroids or anticholinergics, there were no differences between the low- and high-scoring groups. Further, there were no correlations between CSS-SHR scores and any use of medication among the patients.

\section{Discussion}

In summary, the results of this study illustrated that a majority (62\%) of patients with COPD claimed to be hyperreactive to chemicals and scents. As a group they scored higher on a questionnaire measuring social and emotional influences of such environmental irritants compared to healthy control subjects (CSS-SHR questionnaire ${ }^{12}$ ). A potential bias is that only control subjects without any airway symptoms were included, but in a population-based study the prevalence of affective and behavioral consequences of odor intolerance (CSS-SHR score $\geq 43$ ) was $19 \%,{ }^{13}$ compared to $25 \%$ in the current study. However, the present number of patients in different age strata was too small to make proper comparisons with the population-based results, which also included all categories of patients as well those with pronounced sensitivity to environmental irritants.

High-scoring patients were more common among patients with a very severe form of COPD and among patients with regular use of $\beta_{2}$-stimulants. They also had significantly more airway symptoms and, in some aspects, greater impaired quality of life than those with low scores. This seems natural in light of their more severe pulmonary illness. On the other hand, increased sensitivity to odorous substances and chemicals might contribute to the negative effects on quality of life noted in the NHP since SHR patients with a high CSS-SHR score, but without any decline of lung function, also have a reduced quality of life. ${ }^{22,26}$ There were no differences between men and women among the patients regarding the CSS-SHR questionnaire scores, and women were not more common in the high-scoring group. These findings are in contrast to earlier studies showing that in the Swedish population and in those with SHR, women scored higher on the CSS-SHR than men. ${ }^{12,13}$ In COPD, high CSS-SHR scores seem to be related to the basic pulmonary illness, and not influenced by sex.

Nonspecific airway responsiveness refers to the ease with which the airways narrow in response to nonallergic or nonsensitizing stimuli. Responsiveness can be measured by direct stimuli, like methacholine and histamine acting directly on the airway smooth muscles or by indirect stimuli like hypertonic saline, mannitol, exercise, and eucapnic hyperventilation..$^{27}$ Both in asthma and COPD, increased airway responsiveness to direct stimuli like methacholine is wellknown and documented. In COPD, this reaction is probably related to the patients' basic airway limitation..$^{27}$ On the other hand, responsiveness to indirect stimuli like hyperventilation is not as evident in COPD as in asthma. ${ }^{28}$

Patients with CPOD and asthma often complain about airway sensitivity to environmental irritants and such symptoms are often believed to be caused by hyperresponsiveness, meaning that airway narrowing follows irritation-induced airway symptoms. There are, however, few studies dealing with reactions from "real life" stimuli and if, for example, perfumed products can provoke bronchial obstruction in COPD, it is to our knowledge not known. In asthma, this knowledge is also limited. ${ }^{29,30}$ The fact still remains that patients claim to respond to such "trigger factors" and not to methacholine or hypertonic saline. Although the role of sensory nerves in airway inflammation and obstruction is controversial, there is a growing body of evidence for sensory nerves mediating many of the symptoms in these patients. ${ }^{31,32}$ The current results are in line with a novel paradigm, the 
"cough hypersensitivity syndrome," which includes patients with well-established airway diagnosis as well as patients with a general hypersensitivity towards environmental irritants, indicating an airway "sensory neuropathy" in different patient groups..$^{33,34}$

SHR patients have pronounced airway sensitivity to environmental irritants like odorous chemicals and scents, but without airflow obstruction, and they are also recognized by increased cough sensitivity to inhaled capsaicin; ${ }^{9-11}$ these two findings are regarded as closely related. Earlier studies reporting augmented capsaicin cough sensitivity in COPD, ${ }^{4,6}$ together with the present results of subjective sensitivity in COPD, indicate that these two findings may be associated. To confirm such an association, capsaicin provocations need to be performed in COPD patients and related to the outcome of the CSS-SHR score. It is hypothesized that in line with increased capsaicin sensitivity in COPD, augmented sensory nerve reactivity develops together with more severe airway symptoms and impaired lung function. This SHR should be discriminated from airway hyperresponsiveness that is induced by direct or indirect stimuli. However, findings from an earlier study found that cough sensitivity to inhaled capsaicin was independent of the degree of airway obstruction in COPD, but the value of this report may be limited due to the small number of patients who were tested. ${ }^{4}$

In conclusion, the results of this study show that airway symptoms induced by environmental irritants are common in patients with COPD and that this increased airway sensitivity follows the impairment of lung capacity. The mechanisms behind this remain unclear.

\section{Acknowledgments}

This study was supported by grants from the Vårdal Foundation, the Regional Health Care Authority of West Sweden, the Swedish Heart and Lung Foundation, and the Swedish Cancer and Allergy Fund. The authors are grateful to Inger Winberg for excellent help with the data collection.

\section{Disclosure}

The authors report no conflicts of interest in this work.

\section{References}

1. Karlsson JA, Sant'Ambrogio G, Widdicombe J. Afferent neural pathways in cough and reflex bronchoconstriction. J Appl Physiol. 1988;65(3):1007-1023.

2. Midgren B, Hansson L, Karlsson JA, Simonsson BG, Persson CG. Capsaicin-induced cough in humans. Am Rev Respir Dis. 1992;146(2): 347-351.

3. Fuller RW, Dixon CM, Barnes PJ. Bronchoconstrictor response to inhaled capsaicin in humans. J Appl Physiol. 1985;58(4):1080-1084.
4. Doherty MJ, Mister R, Pearson MG, Calverley PM. Capsaicin responsiveness and cough in asthma and chronic obstructive pulmonary disease. Thorax. 2000;55(8):643-649.

5. Wong $\mathrm{CH}$, Morice $\mathrm{AH}$. Cough threshold in patients with chronic obstructive pulmonary disease. Thorax. 1999;54(1):62-64.

6. Terada K, Muro S, Ohara T, et al. Cough-reflex sensitivity to inhaled capsaicin in COPD associated with increased exacerbation frequency. Respirology. 2009;14(8):1151-1155.

7. Caress SM, Steinemann AC. A review of a two-phase population study of multiple chemical sensitivities. Environ Health Perspect. 2003;111(12):1490-1497.

8. Kipen HM, Hallman W, Kelly-McNeil K, Fiedler N. Measuring chemical sensitivity prevalence: a questionnaire for population studies. $\mathrm{Am} \mathrm{J}$ Public Health. 1995;85(4):574-577.

9. Millqvist E, Bende M, Löwhagen O. Sensory hyperreactivity - a possible mechanism underlying cough and asthma-like symptoms. Allergy. 1998;53(12):1208-1212.

10. Millqvist E. Cough provocation with capsaicin is an objective way to test sensory hyperreactivity in patients with asthma-like symptoms. Allergy. 2000;55(6):546-550.

11. Johansson A, Millqvist E, Nordin S, Bende M. Relationship between self-reported odor intolerance and sensitivity to inhaled capsaicin: proposed definition of airway sensory hyperreactivity and estimation of its prevalence. Chest. 2006;129(6):1623-1628.

12. Nordin S, Millqvist E, Lowhagen O, Bende M. A short chemical sensitivity scale for assessment of airway sensory hyperreactivity. Int Arch Occup Environ Health. 2004;77(4):249-254.

13. Johansson A, Bramerson A, Millqvist E, Nordin S, Bende M. Prevalence and risk factors for self-reported odour intolerance: the Skovde population-based study. Int Arch Occup Environ Health. 2005;78(7): $559-564$.

14. Mahler DA. How should health-related quality of life be assessed in patients with COPD? Chest. 2000;117(Suppl 2):54S-57S.

15. French CT, Fletcher KE, Irwin RS. A comparison of gender differences in health-related quality of life in acute and chronic coughers. Chest. 2005;127(6):1991-1998.

16. Tsukino M, Nishimura K, Ikeda A, Koyama H, Mishima M, Izumi T. Physiologic factors that determine the health-related quality of life in patients with COPD. Chest. 1996;110(4):896-903.

17. Hunt SM, McKenna SP, Williams J. Reliability of a population survey tool for measuring perceived health problems: a study in patients with osteoarthrosis. J Epidemiol Community Health. 1981;35(4):297-300.

18. Jans MP, Schellevis FG, van Eijk JT. The Nottingham Health Profile: score distribution, internal consistency and validity in asthma and COPD patients. Qual Life Res. 1999;8(6):501-507.

19. Ozalevli S, Karaali H, Cankurtaran F, Kilinc O, Akkoclu A. Comparison of Short Form-36 Health Survey and Nottingham Health Profile in moderate to severe patients with COPD. J Eval Clin Pract. 2008;14(4):493-499.

20. European Respiratory Society. ERS/ATS COPD Guidelines. Available from: http://www.ersnet.org/lrPresentations/copd/files/patients.html. Accessed May 1, 2010.

21. Bramerson A, Nordin S, Bende M. Clinical experience with patients with olfactory complaints, and their quality of life. Acta Otolaryngol. 2007;127(2):167-174.

22. Millqvist E, Löwhagen O, Bende M. Quality of life and capsaicin sensitivity in patients with sensory airway hyperreactivity. Allergy. 2000;55(6):540-545.

23. Patrick DL, Deyo RA. Generic and disease-specific measures in assessing health status and quality of life. Med Care. 1989; 27(Suppl 3):S217-S232.

24. McKenna SP, Hunt SM, McEwen J. Weighting the seriousness of perceived health problems using Thurstone's method of paired comparisons. Int J Epidemiol. 1981;10(1):93-97.

25. World Medical Association. Declaration of Helsinki: Ethical Principles for Medical Research Involving Human Subjects. Seoul, Korea: World Medical Association; 2008. 
26. Ternesten-Hasseus E, Lowhagen O, Millqvist E. Quality of life and capsaicin sensitivity in patients with airway symptoms induced by chemicals and scents: a longitudinal study. Environ Health Perspect. 2007;115(3):425-429.

27. Hassan NM, Hargreave FE, Nair P. Airway responsiveness to indirect challenges in COPD. COPD. 2010;7(2):133-140.

28. Postma DS, Kerstjens HA. Characteristics of airway hyperresponsiveness in asthma and chronic obstructive pulmonary disease. Am J Respir Crit Care Med. 1998;158(5 Pt 3):S187-S192.

29. Millqvist E, Löwhagen O. Methacholine provocations do not reveal sensitivity to strong scents. Ann Allergy Asthma Immunol. 1998;80(5): 381-384.

30. Opiekun RE, Smeets M, Sulewski M, et al. Assessment of ocular and nasal irritation in asthmatics resulting from fragrance exposure. Clin Exp Allergy. 2003;33(9):1256-1265.
31. Bessac BF, Jordt SE. Breathtaking TRP channels: TRPA1 and TRPV1 in airway chemosensation and reflex control. Physiology (Bethesda). 2008;23:360-370.

32. Geppetti P, Materazzi S, Nicoletti P. The transient receptor potential vanilloid 1: role in airway inflammation and disease. Eur J Pharmacol. 2006;533(1-3):207-214.

33. Morice AH, Faruqi S, Wright CE, Thompson R, Bland JM. Cough hypersensitivity syndrome: a distinct clinical entity. Lung. 2011; 189(1):73-79.

34. Morice AH. The cough hypersensitivity syndrome: a novel paradigm for understanding cough. Lung. 2010;188 Suppl 1:S87-S90.

International Journal of COPD

\section{Publish your work in this journal}

The International Journal of COPD is an international, peer-reviewed journal of therapeutics and pharmacology focusing on concise rapid reporting of clinical studies and reviews in COPD. Special focus is given to the pathophysiological processes underlying the disease, intervention programs, patient focused education, and self management protocols.

\section{Dovepress}

This journal is indexed on PubMed Central, MedLine and CAS. The manuscript management system is completely online and includes a very quick and fair peer-review system, which is all easy to use. Visit http://www.dovepress.com/testimonials.php to read real quotes from published authors.

Submit your manuscript here: http://www.dovepress.com/international-journal-of-copd-journal 